\title{
NUMERICAL ANALYSIS OF A CANTILEVER BEAM AND VALIDATION USING THEORETICAL METHODS WITH APPLICATION TO UNIT DELIVERY
}

\author{
dominic Onimowo ${ }^{1}$ and Emmanuel Onimowo ${ }^{2}$ \\ ${ }^{1}$ Colchester Institute \\ ${ }^{2}$ Anglia Ruskin University
}

May 5, 2020

\begin{abstract}
This paper investigates the deflection and bending stress in a cantilever beam of uniform rectangular cross section with a point load using a 3D Finite Element (FE) model. The results are validated using the Bernoulli-Euler's elastic curve theory equations. The research aims to study and analyse the static analysis of a rectangular beam considered to be isotropic. During this analysis, the displacement is assumed to be small, the material exhibits a linear stress strain relationship i.e.: obeys Hooke's law, there is no change of magnitude, orientation or distribution of the load applied and the effect of gravity are negligible hence with of the beam is not accounted for in this analysis. The simulation is carried out in the Autodesk Inventor stress analysis environment and validated using theoretical methods after which the effects of point loads on structural integrity and mechanical properties are studied.
\end{abstract}

Key Words: Cantilever beam, Finite Element Modelling (FEM), deflection, Bending, Finite Element Analysis (FEA)

\section{Introduction}

Beams are invaluable structural elements. Their application ranges from multi-storey buildings to Micro Electro Mechanical Systems (MEMS) [4]. As a lecturer, it is important to be confident in the software you use and teach in order to pass that confidence along to the students. Autodesk Inventor which is a 3D modelling software has an integrated stress analysis environment. Autodesk Inventor is an invaluable tool in teaching Computer Aided Design (Engineering Design) and Computer Aided manufacture (Toolpath generation and Computer Numerical Control (CNC) programming) hence the importance of being able to link it with theory in engineering as a means of visualising Bending beam stresses, deflection and theories cannot be over emphasises especially for visual learners.

\subsection{Problem Description}

This is a simple structural analysis of a cantilebver beam. The load of $50 \mathrm{~N}$ is applied on the right end of the beam while the left end is constrained (fixed). The objective of this problem is to demonstrate the usefulness of Autodesk Inventor in introducing learners to Finite Emlement Modelling and Analaysis and explain visually using simulations the Bernoulli-Euler's elastic curve theory equations

\section{Numerical Analysis}

\subsection{Finite Element Method}

Figure 4: beam dimensions Schematic 
The governing equations for this analysis are the Bernoulli-Euler's elastic curve theory [5] equations as shown below.

Moment of Inertia, $I=\frac{\mathrm{b} \times h^{3}}{12}(1)$

Maximum Deflection, $\hat{y}=\frac{-W L^{3}}{3 E I}(2)$

Maximum Bending Stress. $\sigma=\frac{M \hat{y}}{I}(3)$

The first step is to generate a $3 \mathrm{D}$ Cad model as shown in figure 1. The constrains and loads are then applied to the beam (figure 2) after which a mesh is generated (figure 3 ).

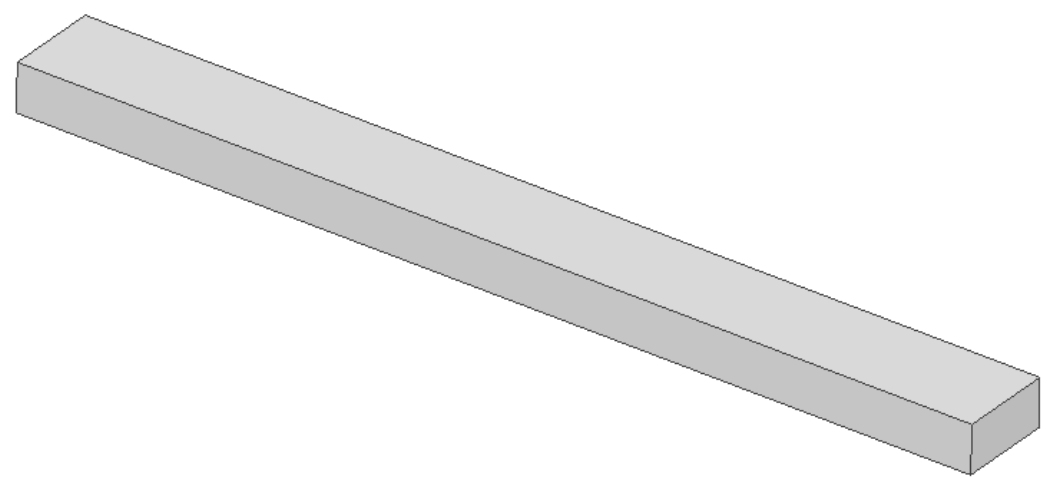

Figure 1: Figure 1: 3D CAD beam model

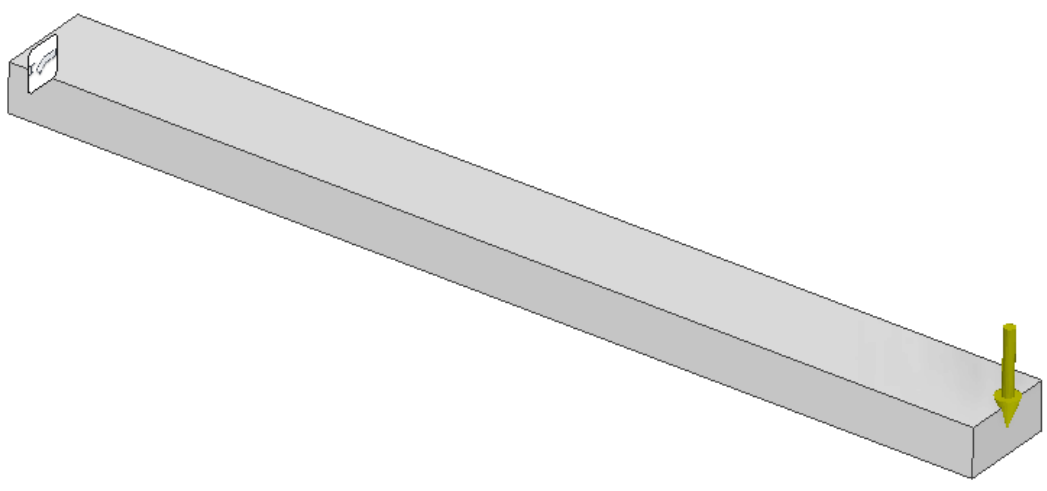

Figure 2: Figure 2: Constraint and Applied load on beam 


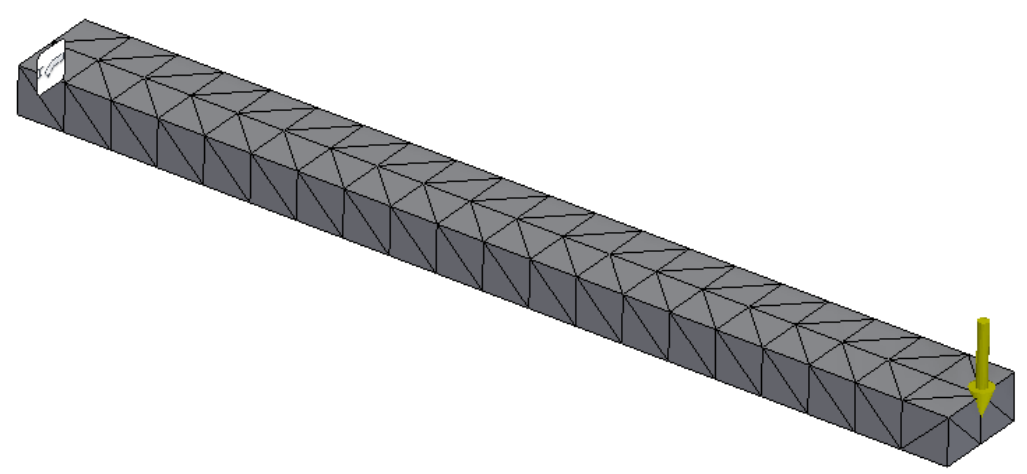

Figure 3: Figure 3: Mesh generated on Beam

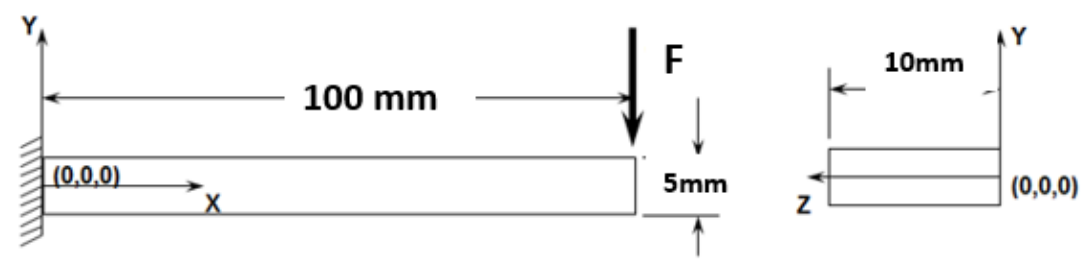

Figure 4: Figure 4: beam dimensions Schematic

\section{Theoretical Validation}

Table : Material properties

\begin{tabular}{llll}
\hline Material Used & Young's modulus (E) & Poisson's Ratio $(\nu)$ & Yield Strength \\
\hline Steel & $210 \mathrm{GPa}$ & 0.3 & $207 \mathrm{MPa}$ \\
\hline
\end{tabular}

Area, $\mathbf{A}=5 \times 10^{-5} \mathrm{~m}^{2}$

Moment of Inertia, $I=\frac{b \times h^{3}}{12}=10.42 \times 10^{-9} \mathrm{~m}^{4}$

Maximum Deflection, $\hat{y} \quad($ at $L=10)=\frac{-W^{3}}{3 E I}=0.761 \mathrm{~mm}$

Maximum Bending Stress. $\sigma=\frac{\mathbf{M} \hat{y}}{\mathrm{I}}=36.57 \mathrm{MPa}$

Safety factor $=\frac{\text { Yield Strength }}{\text { Maximum allowable stress }}=\mathbf{1 . 8 3}$ 


\section{Numerical Results and discussion}

Von Mises stress which depicts the total stress or maximum stress a part can take at a specified loading condition is shown in figure 5 . At $50 \mathrm{~N}$ load, the maximum allowable stress on the component is $113.2 \mathrm{MPa}$.

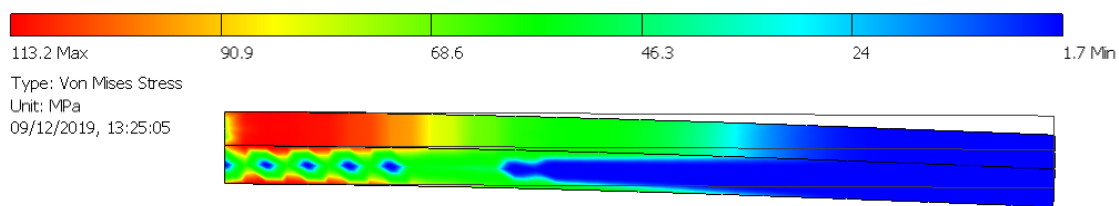

Figure 5: Von Mises stress at 50N point load

In figure 6 , we have the results for the 3rd principal stress. The result is useful to us as our force is compressive and as is correlated from our maximum bending stress calculation, this result is reliable. At $50 \mathrm{~N}$ compressive load, the 3rd principal stress is $37.3 \mathrm{MPa}$. The 1st principal stress result is useful where a tensile load is in effect on the component.

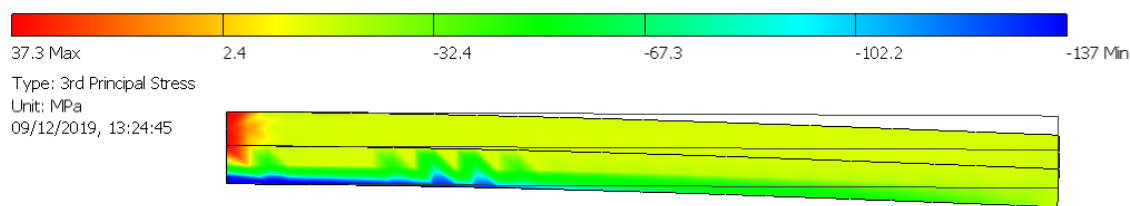

Figure 6: 3rd principal Stress (Compressive loads) at 50N point load

The maximum displacement or deflection is the farthest the component has moved due to the load in effect. This result is visible in figure 7 as $0.758 \mathrm{~mm}$.

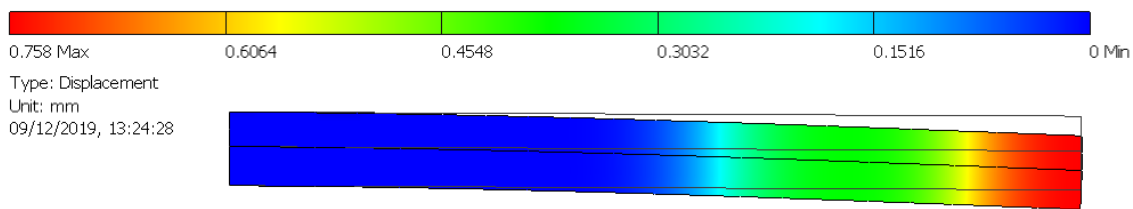

Figure 7: Maximum displacement at 50N point load

The safety factor which is a ration of the material yield strength to the maximum allowable stress is an important design parameter. This result can be seen in figure 8 and the value read as 1.83.

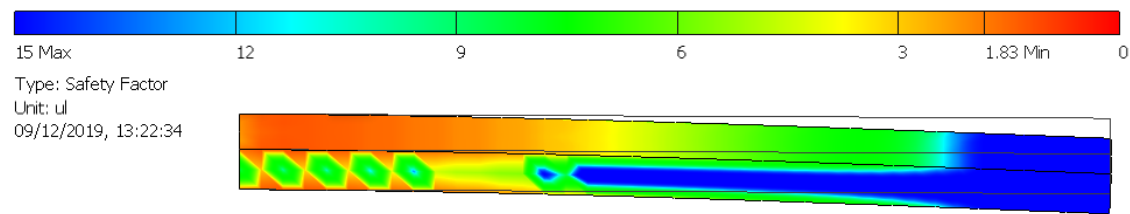

Figure 8: Safety Factor at 50N point load

Table 2: Table of Results 


\begin{tabular}{lllll}
\hline Load $(\mathrm{N})$ & Displacement $(\mathrm{mm})$ Numerical & Displacement $(\mathrm{mm})$ theoretical & Displacement $(\mathrm{mm})$ theoretical & Error \\
\hline $\mathbf{5 0}$ & $\mathbf{0 . 7 5 8}$ & $\mathbf{0 . 7 5 8}$ & $\mathbf{0 . 7 6 1}$ & 0.00394218 \\
$\mathbf{6 0}$ & $\mathbf{0 . 9 0 9}$ & $\mathbf{0 . 9 0 9}$ & $\mathbf{0 . 9 1 4}$ & 0.00547046 \\
$\mathbf{7 0}$ & $\mathbf{1 . 0 6 1}$ & $\mathbf{1 . 0 6 1}$ & $\mathbf{1 . 0 6 7}$ & 0.00562324 \\
$\mathbf{8 0}$ & $\mathbf{1 . 2 1 3}$ & $\mathbf{1 . 2 1 3}$ & $\mathbf{1 . 2 1 9}$ & 0.00492206 \\
$\mathbf{9 0}$ & $\mathbf{1 . 3 6 4}$ & $\mathbf{1 . 3 6 4}$ & $\mathbf{1 . 5 2 4}$ & 0.00510576 \\
$\mathbf{1 0 0}$ & $\mathbf{1 . 5 1 6}$ & $\mathbf{1 . 5 1 6}$ & & 0.00524934 \\
\hline
\end{tabular}

\section{Conclusions}

The simulation and theoretical results of the cantilever steel beam analysis have been carried out and the following conclusion can be drawn,

- the results deduced from the simulation are reliable as visible in the table of results in Table 1 and the graph in figure with miniscule error ranges

- the safety factor or factor of safety which is an important parameter in engineering design can be quite easily deduced from this analysis using the Von mises stress which details the maximum stress on the part and the Yield strength of the material used.

- the simulation is relatively easy to setup and run and the results easy to understand

- the load and displacement can be correlated as shown in figure 9. This is seen to be a linear relationship as defined earlier in the paper.

- This set up and analysis can be used to introduce and deliver basic FEA knowledge and understanding to learners

\section{[CHART]}

Figure 9: Load Vs displacement graph

\section{References}

1. Arun Kumar, S., Velmurugan, V., Paramasivam, V. and Thanikaikarasan, S. (2019). Mesh8Modal analysis of stainless-steel cantilever beam crack dynamics using finite element method. Materials Today: Proceedings.

2. Butt, J. and Shirvani, H. (2018). Experimental analysis of metal/plastic composites made by a new hybrid method. Additive Manufacturing, 22, pp.216-222.

3. Butt, J., Onimowo, D.A., Gohrabian, M. et al. Front. Mech. Eng. (2018) 13: 528. https://doi.org/10.1007/s11465-018-0502-1

4. Kumar Choubey, A. (2012). Static Analysis of Mild Steel Cantilever Beam by Finite Element Modeling.

5. Mills, N. (2007). Polymer Foams Handbook.

6. S. Abhinav Kasat \& Valsson Varghese, "Finite Element analysis of prestressed concrete beams", International Journal of Advanced Technology in Civil Engineering, Vol. No. 1, Issue no.- 3,4, Page no. 29-33, 2012

7. Vanam B. C. L., Rajyalakshmi M. and Inala R., "Static analysis of an isotropic rectangular plate using finite element analysis (FEA)", Journal of Mechanical Engineering Research, Vol. No. 4, Issue no. 4, Page no. 148-162, 2012. 